Fenwick, A., Minty, S. \& Priestley, M. (2013). Swimming against the tide: A case study of an integrated social studies department. Curriculum Journal.

\title{
Swimming against the tide: a case study of integrated social studies department
}

\author{
Ashley J.J. Fenwick, Sarah Minty, Mark Priestley \\ School of Education, University of Stirling, Stirling, Scotland \\ Correspondence details: Ashley Fenwick, Education Lecturer, School of Education, \\ A20a Pathfoot Building, University of Stirling. Stirling, FK9 4LA, 01786466134 \\ ashley.fenwick@stir.ac.uk
}

Ashley Fenwick is a lecturer in the School of Education at University of Stirling. Her research interests include curriculum change, outdoor learning and early professional learning.

Sarah Minty was formerly a Research Fellow for the project 'Building Upon Success: extending and sustaining curriculum change in Highland' in the School of Education, University of Stirling. She is currently employed in the Moray House School of Education, University of Edinburgh.

Mark Priestley is Professor of Education in the School of Education at the University of Stirling, where he is currently Director of the Curriculum and Pedagogy Research . He is Chair of the Editorial Board for the Scottish Educational Review and a Council Member for the British Education Research Association 
Fenwick, A., Minty, S. \& Priestley, M. (2013). Swimming against the tide: A case study of an integrated social studies department. Curriculum Journal.

\title{
Swimming against the tide: a case study of an integrated social studies department
}

\begin{abstract}
A recent trend in developed countries' school curricula has been the transition from disciplinary to generic forms of knowledge, resulting in an emphasis on interdisciplinary organisation and more active forms of learning. Subject specialists are increasingly expected to demonstrate how their subject interconnects and equips pupils with key life skills. Such a change requires a major cultural shift and has been controversial, particularly in Scotland where Curriculum for Excellence, the latest curriculum reform, has seen this debate re-emerge. A detailed empirical case study of one secondary school Social Studies department that has already negotiated these shifts is presented. The case study provides insights into how school and department structures and cultures conducive to a more integrated approach have been developed. Leadership, increased opportunities for teachers to exercise greater autonomy in their work, sources of impetus and support for innovation, and the co-construction of meaning through dialogue are important themes in this process. This case study connects with current policy and provides an insight into strategies that other schools might employ when seeking to embed integrative practices. The department is identified as a significant locus for innovation and one which appears to challenge the norm.
\end{abstract}

Keywords: curriculum change; culture; structure, Curriculum for Excellence; Social Studies; integration.

\section{Introduction}

Curriculum policy initiatives across the developed world are characterised by a number of common trends in response to $21^{\text {st }}$ century challenges (Broadhead 2001; Tan et al. 2007). The role of schools in developing knowledge and skills for both the workplace and citizenship is highlighted in many modern curricula. One aspect of this has been a shift from traditional subject-based curricula, with an emphasis on foundational knowledge, examinations and didactic teaching, towards a more technicalinstrumentalist approach, with an emphasis on skills and application of knowledge (Young and Muller 2010). In many countries, this transition from disciplinary to generic forms of knowledge has been accompanied in secondary schools by a greater emphasis 
Fenwick, A., Minty, S. \& Priestley, M. (2013). Swimming against the tide: A case study of an integrated social studies department. Curriculum Journal.

on interdisciplinary curricular organisation and more active forms of learning (Hargreaves and Fullan 2000; Whitty 2010). Subject specialists are thus increasingly expected to illustrate how their subject both interconnects with other subjects, and equips pupils with key life skills (Young 2008). Scotland is, in many ways, typical of these trends; its new Curriculum for Excellence (CfE) (Scottish Executive [SE] 2004) endorses 'greater cross-subject activity' and space for activities that 'broaden the life experiences - and life chances - of young people' (4). In recent years, one response to such developments has been moves to develop a more integrated. approach to defining school knowledge/content - for example, the bringing together of Geography, History, and Modern Studies to form a new amalgamated subject, Social Studies. However, such change is dependent on a major cultural shift within schools. The difficulties inherent in the translation of central curriculum policy into practice are welldocumented (Osborn et al. 1997; Supovitz 2008) - CfE is no exception (Priestley and Humes 2010; Minty and Priestley 2011; Priestley and Minty 2012). The focus of this paper is curriculum change and how it is enacted. The context for this analysis lies in the shift from a subject-centric to a more interdisciplinary approach. The associated cultural and relational implications of this process are discussed through the analysis of empirical evidence from one secondary school Social Studies department that has enacted an alternative approach to integrated Social Studies and has developed a strong unified 'Social Studies' identity amongst its teachers. This contrasts with many other Scottish schools where subject divisions and tensions remain (Bryce and Humes 2008; Minty and Priestley 2011). As such, it provides a powerful example of how a school might 'swim against the tide' in enacting controversial curriculum change, and offers a useful insight into strategies that other schools might employ when seeking to embed integrative practices. We provide a brief overview of the wider debate around subject integration before outlining the Scottish educational policy context. The Social Studies department provides a setting in which to explore curricular change. This case study therefore offers an original and significant insight into the complexities of curriculum change at school and department level.

\section{The integration debate}

Controversy and recurrent debates relating to disciplinarity and interdisciplinarity (Bernstein 1971; Whitty 2010 Moore 2011), the organisation and purpose of knowledge 
Fenwick, A., Minty, S. \& Priestley, M. (2013). Swimming against the tide: A case study of an integrated social studies department. Curriculum Journal.

(White 2005; Young 2008) and associated pedagogies (Kress 2000) are not new (for a useful summary see Venville et al. 2002). An international trend away from a curriculum organised around discrete subjects towards a more integrated ${ }^{1}$ and interdisciplinary model is apparent in junior secondary schools across the developed world (Benavot 2004; Geraedts et al. 2006; Applebee et al. 2007). Social Studies may lend itself to such an approach, as multiple perspectives can be brought together to problem solve current issues relating, for example, to citizenship or education for sustainable development (Beane 1997; Jacobs 1997; Harris et al. 2011). Examples of successful interdisciplinary working that is collaborative, integrated across departments and proceeds from and strengthens disciplinary thinking is well documented (Sweerts and Grice 2002; Byrom 2010; Monaghan 2010). However, challenges are also evident. Harris et al. (2011) identify coherence, progression, assessment and content selection as areas that require considerable attention. Criticisms levelled at less successful forms of general cross-curricular working include: reduced teacher and pupil enthusiasm, a lack of depth in relation to knowledge and subject specific skills, minimal opportunities for high-order discussion (Exley and Singh 2011) and the prioritisation of one subject at the expense of others (Hillis 2010; Lambert 2011). Limited time and resources for planning and implementing integrated approaches have also been highlighted as barriers to successful enactment of such initiatives (Harris and Ratcliffe 2005; Applebee et al. 2007). The central role that disciplines and disciplinary thinking play in relation to planning and implementing interdisciplinary working is highlighted by Harris et al. (2011) and Mintrop (2004). Disciplinary thinking has also evolved: fostering greater pupil, autonomy and creativity (Lévesque 2008; Seixas and Peck 2004), developing high order thinking (Rudham 2001; Banham 1998; Leat 1998; Anthony 2009), reinforcing real world relevance (Schleppegrell 2011; Wrenn 1999) and increasing pupil motivation (Burnham 2007; Foster 2008 - for some practitioners this may negate the need for interdisciplinary working.

The move towards integrated faculties or departments is thus contentious, as outlined, and may run counter to existing school practices, cultures of subject and school organisation and teacher beliefs (Siskin 1994; Harris et al 2011; Minty and Priestley 2011). Research strongly suggests that for change to be sustained, it is 
Fenwick, A., Minty, S. \& Priestley, M. (2013). Swimming against the tide: A case study of an integrated social studies department. Curriculum Journal.

necessary to address the cultures and structures of schooling (Ball and Lacey 1980; Siskin 1994). Broadly speaking, culture relates to the norms, attitudes, beliefs and knowledge forms that represent schooling (Archer 1988). Structures are the patterns of relationships and roles that form social organisations like schools, along with their emergent properties (for example, power - see Elder-Vass 2008). Culture and structure operate symbiotically; for example in school, notions about student behaviour may lead to the formation of systems and roles to maintain discipline, and in turn such systems and roles reinforce notions about student behaviour, et cetera. Many writers have commented on how the prevalent structures and cultures of schooling reinforce existing patterns of practice - what Tyack and Cuban (1994) referred to as the grammar of schooling. Eisner (1992) identified structural fragmentation of schools as one of the most problematic factors of school organisation. McGinley and Grieve (2011) recognised that weak communication networks imposed by hierarchical structures and limited opportunities for joint working within secondary schools, were problematic.

These cultures and structures are evident in the strongly bounded nature of subject disciplines in schools (Bernstein 1971; Olson et al. 1999; Jephcote and Davies 2007). Subject disciplines have multiple functions, providing professional support, a political base, an organisational unit for the development and dissemination of learning and teaching materials, a comfort zone and links to wider coalitions within the subject community. A long history of competition prevails between secondary school subjects: 'the department [being] the singular entity that most predictably unites teachers with one another, and most deeply divides faculty groups from one another' (Siskin and Little 1995, 7). - Secondary teachers' professional identities are also often strongly grounded in a sense of subject specialism (Moore 2011). This identity is closely affiliated to teacher's specialist subject knowledge, skills and status; it is also enmeshed with material interests such as pay, job security, promotion and conditions (Ball and Lacey 1980).

A policy shift towards a more integrated interdisciplinary curriculum therefore presents challenges (Paechter 1995; Robertson et al. 1998; Harris and Ratcliffe 2005; Geraedts et al. 2006; Shulman and Sherin 2007). Little (1995) summarised the tensions which existed, as well as the influence of external and internal factors:

Teachers confront a daily choice between emphasizing subject content and subject mastery, or pursuing broader interdisciplinary topics and questions. Given the 
Fenwick, A., Minty, S. \& Priestley, M. (2013). Swimming against the tide: A case study of an integrated social studies department. Curriculum Journal.

pervasive rhetoric of curriculum coverage, the choice seems always coloured by threat of compromise - what must one give up to make room for the ideas, topics, and materials that bridge subjects? The choice teachers make is swayed in important ways by the external forces that define the scope and organization of school knowledge, but it is also shaped by quite localized expectations for the forms that "teaching" takes and by the subjective realities of "feeling like a teacher (198).

The dichotomy that Little's study described may still resonate with practitioners within some departments (Venville et al. 2002; Priestley and Minty 2012).

\section{Emerging practices in Scotland}

$\mathrm{CfE}$ has seen a resurfacing of the debate around integrated subjects. The new curriculum echoes international trends towards a more skill-based, flexible, creative system and interdisciplinary learning. This presents an opportunity for many departments to reconfigure their approaches to teaching Social Studies in the junior school. Some local authorities have responded to $\mathrm{CfE}$ by merging discrete, individual subject secondary departments into larger composite departments or 'faculties'. This has led to unease in connection with the management of curricular change in non-specialist areas by faculty heads (Bairner 2008).

Two alternative delivery models have arisen in relation to integrated ${ }^{1}$ Social Studies within Scotland, termed multi-disciplinary and interdisciplinary (Priestley 2009). The multi-disciplinary organisational approach involves single teacher delivery of discrete social subjects throughout the year, but they remain as discrete entities or modules. This approach may allow links to be made, though this can remain challenging, especially as many teachers will be non-specialists delivering curricular materials developed by other teachers. Under such circumstances, ownership of the materials and topics is difficult. Research data collected in 2003 (Priestley 2011) suggests that this is the predominant approach in Scottish Social Studies faculties, where some measure of integration between subjects is pursued. The second, interdisciplinary approach comprises an organisational and pedagogical model, involving the cross-curricular and integrated planning of content and skills. The distinction between the constituent subjects is not evident. Interdisciplinary provision differs from multi-disciplinary provision in 
Fenwick, A., Minty, S. \& Priestley, M. (2013). Swimming against the tide: A case study of an integrated social studies department. Curriculum Journal.

that there is some attempt to blur the boundaries between the constituent subjects, through the employment of organising themes. Thorough planning and effective collaboration is essential. This model has not been common in Scotland. Attainment statistics, Her Majesty's Inspectorate of Education ${ }^{2}$ [HMIE] (as it then was), and timetabling exert influence over what is taught in secondary schools (Biesta 2004; Reeves 2008; Boyd 2008). Such factors have militated against greater integration in the majority of Social Studies departments. It is also important to note that the majority of new Scottish teachers entering the profession to date have been single subject qualified ${ }^{3}$. However, as CfE is implemented more schools may consider this approach. The remainder of this paper will focus on the department structures and cultures of one Scottish secondary school case study, Hill Brae, that has enacted an alternative integrated approach to Social Studies. This paper provides a detailed empirical case study of how one secondary school has negotiated these shifts and successfully implemented curriculum change.

\section{Research design}

This article draws upon case study data collected in one Scottish school in 2006. The data was gathered as part of a pilot comparative study of differing forms of Social Studies provision in three Scottish schools. The project, 'Departmental cohesion and the social subjects - culture, identity and the management of change' aimed to: identify key characteristics of successful school departments; investigate how teacher identity and personal philosophies relate to provision, pedagogy and approaches to enacting change; and investigate how departmental organisation relates to provision, pedagogy and approaches to enacting change. A number of teachers were interviewed in each of the three schools. Key research questions were:

- What is the nature and extent of provision of Social Studies in secondary schools?

- How are the school departments organised and what social relations exist within them? What ideas underpin the development of Social Studies?

- What are the backgrounds of teachers who contribute to Social Studies courses? 
Fenwick, A., Minty, S. \& Priestley, M. (2013). Swimming against the tide: A case study of an integrated social studies department. Curriculum Journal.

- What methods are used in the teaching of Social Studies and how do these relate to the provision, philosophy, departmental organisation and teachers' backgrounds?

Taking the research questions as a starting point, two researchers coded the data from the three schools independently using an open coding approach to generate descriptive codes. The researchers then shared and discussed these codes, providing an opportunity to reduce researcher bias and ensure inter-rater reliability. The descriptive codes of the two researchers were agreed and merged, before finally interpreting the data according to the research questions. Having coded the data from the three schools, it was clear that they represented a continuum from discrete Social Studies provision in one school, to early integration in a second school, and finally full integration in the third school. For the purposes of this paper, we have focused on data from the third school, Hill Brae (a pseudonym). This provided an interesting case, having employed an interdisciplinary approach to Social Studies in the junior school (S1 and S2) for many years. We draw upon data from four one-hour semi-structured interviews, conducted with Principal Teachers from Geography, History and Modern Studies and one class teacher of History and Modern Studies. The codes were grouped into four key themes which appeared to contribute towards the success of the integrated social studies approach - leadership; teacher identity; departmental ethos; and physical layout. Pseudonyms are used throughout the paper for the school and individuals. The research adheres to Ethical Guidelines for Educational Research of the British Educational Research Association.

Our aim in the paper is to identify and explore key characteristics of a department that has developed and sustained a curricular initiative that goes against the current organisational and structural tide in Scotland (Priestley 2009).

\section{School context}

Hill Brae is a small non-denominational comprehensive secondary school with a roll of approximately 550 pupils and more than 40 full time teaching staff. The school has a mixed suburban and rural catchment area. At the time of the research, the school was unusual in that the headteacher had been in post since the school opened, for about 25 years at the time. Pupil attendance is currently in line with the national average and 
Fenwick, A., Minty, S. \& Priestley, M. (2013). Swimming against the tide: A case study of an integrated social studies department. Curriculum Journal.

examination results are slightly above the national average. The number of students receiving free school meals is well below the national average. At the time of the research, in S1 and S2 (the first two years of secondary school - ages 11-13) classes were mixed ability and class sizes were smaller than average with approximately 20 pupils. Pupils followed a common course, which included 2.5 hours a week of Social Studies. The school delivered a full range of secondary courses; the S5/S6 (senior) curriculum was jointly programmed with a neighbouring secondary school.

An integrated approach to Social Studies was embedded in Hill Brae and had been in place since the school opened. This philosophy was made clear during the interview process to prospective employees at Hill Brae and staff recruitment was aligned to this viewpoint. This preceded a policy and curricular emphasis on a more joined up approach to the secondary curriculum and interdisciplinary working. Pupils sat one less Standard Grade ${ }^{4}$ in order to study a short course, such as first aid, thinking skills, environmental education or enterprise; all teachers were encouraged to contribute to these co-curricular courses.

The Social Studies Department consisted of five teachers - three of these teachers were Principal Teachers with responsibility for the History, Geography and Modern Studies externally examined courses from S3 to S6. The four teachers interviewed were all well established in the school, and had worked there for between 8 and 20 years. All Social Studies staff were dual-qualified to teach more than one subject. Three of the staff had previous experience of teaching more than one Social Studies subject in other schools. Social Subject meetings were attended by all relevant staff and courses were developed collaboratively. Individual subject meetings were also held for middle and senior school classes. The competitive element commonly found between subjects particularly in relation to option choices was not evident amongst these teachers.

Interviewees explicitly highlighted the integrated nature of Social Studies within Hill Brae. The school had developed a particular way of working for S1 and S2 Social Studies, which was delivered to each class by the same teacher throughout the year. Topics were taught through themes such as Early Settlers and Voyages of Discovery. 
Fenwick, A., Minty, S. \& Priestley, M. (2013). Swimming against the tide: A case study of an integrated social studies department. Curriculum Journal.

The physical layout of the department was considered conducive to a collaborative and flexible style of teaching. S1 and S2 Social Studies classes were held in a designated open plan area located close to the school library, which was used by all four teachers when teaching junior classes. Team teaching took place regularly across two classes. A range of pedagogies were employed to support pupil learning - investigation work, visiting speakers, role play, active learning and field work. At the end of these two years of study pupils decide what subjects they would like to study in the S3 and S4 examination years.

\section{Research findings}

Four key factors which enhance the success of the integrated SS model relating to departmental culture emerged from the data. These are leadership and ethos, teacher identity, departmental ethos, and space and curriculum architecture.

\section{Leadership and ethos}

A supportive school leader with a strategic vision appears to have nurtured and supported this model. The headteacher of Hill Brae was well established within the school and was perceived to challenge external policy trends. In some cases, the culture within Hill Brae was at odds with external priorities; for example, the exam focussed nature of the curriculum and the emphasis on discrete subjects promoted by, the then, HMIE. A forward thinking, pupil centred vision and strong leadership was described in the narratives of all four teachers. This was evidenced by opportunities to study short courses in S3/4 in place of one of the traditional Standard Grade examination options. This demonstrated a broad recognition of achievement and attainment beyond academic results. Respondents described opportunities for staff to work across departments and undertake a range of professional development opportunities, which both created greater collaboration, and reduced subject delineation. The head teacher's leadership practices within Hill Brae exemplified what Priestley et al. (2011) refer to as an experimental culture of professional enquiry, where 'supportive and facilitative management' provides 'official permission (and encouragement) for experimentation' (280), thus contributing to the success of an educational change initiative.

An expansive understanding of the purposes of schooling, the curriculum and educational values was apparent in the management of this school, with clear 
Fenwick, A., Minty, S. \& Priestley, M. (2013). Swimming against the tide: A case study of an integrated social studies department. Curriculum Journal.

implications for curriculum-making practices. Teachers explained that the headteacher had exerted a strong consistent influence and firmly embedded vision.

No, it's the ethos here that I think is quite different. It comes from the top; it comes from the HT. [...] he really sees education as more than bits of paper, hence the one less Standard Grade (First Aid instead and Thinking Skills), and encourages the kids to really think for themselves. And I suppose it's maybe his influence right from the start that set up the Social Studies and we're just reflecting that... (John)

Yes, that's very much the vision of the rector, the same rector after twenty-six years. It's his thumb-print over the school. In terms of philosophy and certainly the curriculum, I could say he was ahead of his time, and certainly very much was the exception, especially in S2, because some schools have gone down an integrated $\mathrm{S} 1$ route, but most have kept the discrete identity in S2... (Mary)

Pro-active recruitment and selection of staff at interview was identified as one of the reasons for the continuation of integrated Social Studies. A teacher said: 'the boss is very astute, we're upfront with people.' (John)

The importance of clear communication of expectations relating to this 'vision' and ethos was highlighted by interviewees. An ethos of co-operation, trust and shared responsibility characterised these teachers' engagement with the Social Studies initiative, supporting the observation of Wubbels and Poppleton (1999) that, when teachers' attitudes and enthusiasm are aligned with an initiative, the likelihood of sustained success is greater. The recruitment policy, whilst important in developing the sustainability of the initiative, does not provide the sole reason for the success of Social Studies at Hill Brae. One teacher stated that although the integrated nature of the junior school curriculum was made clear at interview it had not prepared them for the sense of collegiality that pervaded the department in other areas of the curriculum. Upon joining Hill Brae, the interviewee indicated that it took several years to socialise into the culture of the school. This may support Schien's (1992) claims that an organisation's culture determines what it can and cannot do; the extent of individual members' socialisation into that culture influences their actions. Careful recruitment is likely to speed up this process. 
Fenwick, A., Minty, S. \& Priestley, M. (2013). Swimming against the tide: A case study of an integrated social studies department. Curriculum Journal.

\title{
Teacher identity
}

A strong subject affiliation has been recognised as central to secondary school teacher identity, and is associated with status (Hargreaves 1994a; Siskin and Little 1995; Priestley 2010). Significantly, Social Studies teachers at Hill Brae tended to perceive their role as teachers first and subject specialists second, as demonstrated in this quotation:

\begin{abstract}
Well I would say I teach children first and foremost. I tend to try and teach them skills which are going to be useful to them regardless of which subject they end up doing throughout the school, and regardless of which stage of the school, I try to teach them skills which are going to be useful beyond school. To me the subject is kind of secondary in a lot of cases particularly lower down the school, where we just try and instil good habits and good skills, and I would say that that's the role $\ldots$ and just trying to help them achieve what they can achieve to the best of their ability, whatever that happens to be, and try and give them some fun while they're doing it. (John)
\end{abstract}

The interviewees had a much wider view of their role in relation to developing skills, linkages and real-world learning, and highlighted the importance of contributing to whole school initiatives and the perceived benefits that ensued. Hansen (1999) stated that integrated teaching calls for identity to be developed around pedagogy rather than subject discipline; this is what appears to have happened in Hill Brae. Collaboration also seemed to further the development of a common professional language, which presented an alternative to the pervasive vocabulary of quality control and performance targets that can sometimes dominate schools (Keddie 2011). Opportunities to work in cross subject teams were commonplace in the school.

I think yes, my job is to promote the teaching of modern studies in the school, but I'm more than that. I mean, in this school I've been involved in a lot of whole school initiatives, and a number of extracurricular activities as well. I don't see myself as living only in this department, and I think that's part of the school role. We're encouraged to take part and work in groups for example, and throughout the eighteen years I've been here, I've played a part in the life of the whole school, not just Social Studies. (Mary) 
Fenwick, A., Minty, S. \& Priestley, M. (2013). Swimming against the tide: A case study of an integrated social studies department. Curriculum Journal.

Day et al (2006) state that teacher identity comprises the interactions between professional, situated and personal dimensions. Teachers in Hill Brae indicated an awareness of the context specific nature of teacher identity and challenges faced when implementing a more interdisciplinary approach. Teachers were clear that while it worked in Hill Brae, this was down to the combination of individuals, their backgrounds and interests, and the prevailing culture of the school, and that such working practice would not necessarily translate to other schools.

I've never said that because it works here, it'll work everywhere else, and I think the reasons I gave earlier, about the individuals, the personalities, and the background of people working, but it does work here, and it's succeeded here... (Mary)

We work together; we do quite a lot of things which are cross curricular things, so we don't really feel, because we are part of the way down that road, that that is going to be a big issue. I am not saying I don't think that discrete departments could never work together, I am only thinking of the ones I have experienced and I couldn't see them doing it. I don't necessarily think that is the case everywhere, because, you know, some of my colleagues in the city have started to do more collaborative teaching in first and second year, and some places are more... it works better than others, but I think it does depend on the personnel. (David)

At Hill Brae individual teachers' personal and professional identities and departmental relational dynamics appear to have combined in unique ways to create specific contexts which shaped attitudes towards Social Studies and contributed to the success of the interdisciplinary model. This highlights the difficulties of simply replicating one approach.

\section{Departmental ethos and relationships}

A collaborative and collegiate ethos pervaded the Social Studies department in relation to planning, communication, pedagogy and teaching. The balkanised culture (Hargreaves 1994a; Priestley 2010) commonly found within Scottish secondary schools was not apparent in Hill Brae, where Social Studies was viewed as a coherent unit. This was replaced by what might be described as a strongly bonded culture (Olson et al. 1999), which illustrates the powerful influence department and faculties can exert in 
Fenwick, A., Minty, S. \& Priestley, M. (2013). Swimming against the tide: A case study of an integrated social studies department. Curriculum Journal.

generating robust, meaningful membership within a collegial community (Siskin 1994), and the importance of constructing good relationships, based on trust (Clegg et al. 2002). This sense of collegiality appeared crucial in shaping and sustaining innovation in the school:

We are seen as a unit, there would be quite a few members of staff who could not tell you if I was geography, history or modern studies. They know I am Social Studies and that's quite nice. You know, there are three PTs in the department and they are all my bosses, but we all work together and we are the Social Studies department; that's how we are described; that is how we would be listed in things, and I think we would be well respected as a department. (Joyce)

Lack of subject knowledge and expertise is often cited as a concern of teachers in relation to the delivery of integrated or single teacher delivery of Social Studies (Hillis 2010; Lambert 2011). Harris et al (2011) and Mintrop (2010) emphasised the need for teachers to have a sound grasp of the substantive knowledge and concepts involved in their own subjects before embarking on interdisciplinary initiatives. In Hill Brae there was some evidence to suggest that professional support and development from other members of the team alleviated these concerns. The asymmetric power relations and hierarchies that limited joint working within secondary schools, as reported in McGinley and Grieve's (2011) small case study, were not apparent, except in the clear vision promulgated by the senior management. Instead, many informal and semi-structured opportunities to collaborate, share ideas and materials created a climate of trust in which teachers pooled resources, dealt with emergent problems, and recognised individual strengths. Teachers at Hill Brae appeared to view themselves as learners and recognised individual teacher strengths. Professional development and support was provided from within the department.

Speaking with subject specialists; that is one thing I have quite liked. I'm not a promoted member of the department but, you know, others who are will come to me and ask me how to teach things which is lovely, you know, and we will share ideas. Several members of the department are qualified in two subjects anyway. (Joyce) 
Fenwick, A., Minty, S. \& Priestley, M. (2013). Swimming against the tide: A case study of an integrated social studies department. Curriculum Journal.

There are two people in [the social studies base] together all the time and they're mostly in different subjects. I mean, on Wednesday [colleague] was on one side and I was at the other. We're doing this geography bit in second year and he was telling [his class] about it and a big story about all the stuff, and I just said to my class 'be quiet, listen to him'. He has a big loud voice and he spoke to them all because I didn't have that depth that he was telling them about and I thought 'well I'm not going to compete with him, I'll just let him speak to them all'. (David)

One teacher suggested that she invested more time and effort to compensate for any areas of weakness relating to non-specialist areas of Social Studies. She described geography as her 'weakest subject', explaining that 'I am not qualified in it; I haven't got a degree in it, but I would say it is the one I have worked hardest at'. (Joyce)

The perceived benefits of this approach reported by interviewees were increased continuity and progression, improved pupil teacher relations and regular subject contact time per week, as well as a reduced workload linked to report writing. Teachers highlighted the relational benefits of an integrated approach to Social Studies delivery:

Well, you have got a better relationship with the kids, they learn well, you know, what their needs are. You can focus tasks to meet what they require to get the best out of every topic. (Joyce)

The other thing is, you get to know the pupils so much better. You see them an average of 200 minutes a week, as opposed to forty, maybe fifty-five, so by seeing them more often, more frequently, they get to know you. (Mary)

A point of interest is that the traditional competition relating to pupil subject choice selection at the end of first or second year was not apparent between the Social Studies department within Hill Brae, although there was evidence of competition between other subject areas. David explained:

The school that I was in before was you know, battle lines drawn when it got to choice time in second year and we make a conscious decision not to do that, we want to get as many pupils from first and second year into Social Studies, history, geography or modern studies. (David) 
Fenwick, A., Minty, S. \& Priestley, M. (2013). Swimming against the tide: A case study of an integrated social studies department. Curriculum Journal.

Where there was an imbalance across the three subjects relating to pupil uptake, there was a collective responsibility to address the issue. Teachers described how they 'work together to try and promote' the Social Studies subjects in order to achieve a balance between them. There was some evidence that this collaborative and collegial ethos also pervaded the upper school curriculum. A modern studies teacher spoke of continuing to discuss things with colleagues and working together with senior classes, characteristic of the 'shared' approach to curriculum integration described by Fogarty (1991).

We try wherever possible to point out to the pupils the connections still between the two subjects. When they come to the end of fourth year we say to them, 'Okay you can go into Higher here with your subject, but you can also go into Intermediate 2 in the other Social Studies.' We still see ourselves as a Social Studies department. (John)

In Hill Brae, generic skills were developed through a more integrated approach to topic content and skills. Teachers spoke of developing a shared approach comprising joint planning of related disciplines in order to identify commonalities. They demonstrated a broad appreciation of the application of skills across all three Social Studies. Staff viewed the junior school as an opportunity to develop skills that ran across all three subjects. Preparation for Standard Grade was not the main priority, instead meaningful contextualised learning (Beane 1997) was emphasised.

\footnotetext{
We put an awful lot of emphasis on enquiry skills and things like the identification of bias, that in other places would be seen purely as a part of history, whereas in actual fact it's needed across. We put quite a lot of emphasis on group working and participation .... I just think we've got a much more rounded ethos, and through avoiding repetition. (John)
}

This shared approach was also translated to the leadership and management across the department. Three Principal Teachers worked within the department; however, there was not a dominant member of the team. A teacher explained that they worked in an environment where teachers cooperated, shared workload and trusted each other. Another said: 
Fenwick, A., Minty, S. \& Priestley, M. (2013). Swimming against the tide: A case study of an integrated social studies department. Curriculum Journal.

There's no one person in charge, there are three of us and we share responsibility, no-one is seen as 'the head of the faculty' for example, the other two wouldn't allow it to happen, but I don't think anyone is recognised as such. (Mary)

Teachers demonstrated a shared understanding in relation to systems, procedures, standards and expectations. A high level of consistency and collective responsibility for reinforcing these protocols was described across all three departments.

We all work together rather than being in this department and then in this department, so we all have right up the school the same discipline standards, the same procedures, the same homework expectations.(David)

Individualism can splinter professional relationships, making it hard for teachers to build on one another's expertise and inhibit the moral support necessary for risktaking and experimentation. Hargreaves (1994b) suggests a moving mosaic structure may provide a more dynamic, context sensitive model relating to, blurred subject boundaries, status and organisation. This blurring was evident in relation to school systems, organisation, timetabling, pedagogy and professional development within all three Social Studies subject areas at Hill Brae, as well as across the wider school.

\section{Space and curriculum architecture}

Siskin (1994) identified 'architectural layout' as a key factor in reinforcing departments as social subsets. The close geographical proximity of all three departments in Hill Brae and designated open plan rooms for junior school teaching were identified as integral to the success of Social Studies teaching. This facilitated an open style of teaching and created opportunities for paired and team teaching, as well as formal and informal exchanges between teachers.

We don't have the 'closed doors' syndrome because we have the open plan, we can hear what's going on so we don't have the worries 'my subject', if you want to call it that, being taught properly. (John)

The shared nature of this space seemed symbolic of the ethos, philosophy and supportive relationship which permeated all three departments. The lack of physical boundaries between departments and designated ownership of space to one particular 
Fenwick, A., Minty, S. \& Priestley, M. (2013). Swimming against the tide: A case study of an integrated social studies department. Curriculum Journal.

Social Studies area or teacher enabled and promoted greater collaboration, communication and shared understanding, thus avoiding territorial disputes.

The kids see it as a social subjects area; they don't see it as a geography room being used for Social Studies. We co-operate with things like homework club, study support; we all pitch in and take our turn at doing that. We don't try and run things in competition with each other. And I think us going there rather than the kids coming to us makes a difference to it as well. (John)

The fact that we have areas for the subjects rather than the people is important.... and I think it works. I like having an area for teaching a particular subject because you know where everything is and you get it and you do it and nobody has their own territory, because I think that's another reason why we work so well together because nobody's territorial. (David)

Our analysis of the context for teaching at Hill Brae concurs with McGregor's (2004) work in suggesting that the material and spatial characteristics of the school are significant in helping to shape the cultures and structures within which innovation occurs.

\section{Discussion and implications}

Whilst acknowledging the small scale, context specific nature of this case study and its associated limitations, a number of interesting themes emerge from the research: these relate to leadership, increased opportunities for teachers to exercise some autonomy and engagement, sources of impetus and support for innovation, and the importance of coconstructing meaning through dialogue. Research into effective organisations indicates that creating good relationships on the basis of trust can help to generate an innovative atmosphere in which creativity and change take place (Clegg et al. 2002). The particular characteristics at Hill Brae - small school, practical class sizes of 20, a long established headteacher, and the careful recruitment of enthusiastic and collegial Social Studies staff combined to create ideal conditions for an integrated approach to Social Studies. Teachers acknowledged the difficulties of applying their approach to a new context. The data highlights the importance of considering these ingredients, not simply as isolated factors that can be controlled by the implementation of various strategies on the part of individual policy makers, schools or teachers, but rather as interacting parts 
Fenwick, A., Minty, S. \& Priestley, M. (2013). Swimming against the tide: A case study of an integrated social studies department. Curriculum Journal.

of a culture. This demands that we consider the process of change in a more complex relational manner, analysing how these ingredients come together in their particular enactments in specific settings. This supports Harris et al's (2011) thinking that 'teachers have to find their own way if they are to successfully address cross-curricular learning' (48).

Subject departments have often been characterised as places which can resist change (e.g. Kysilka 1998; Siskin 1994; Olson et al. 1999; Wubbels and Poppleton 1999). Our research seems to support Siskin's (1994), view that 'as social worlds, departments both provide a potential site for strong and meaningful membership within a collegial community, and out of that community generate a cultural mechanism which can reinforce, mediate or transform school culture' (92). The research indicates that departments need not be sites of resistance to change or of retrenchment - although clearly many become so. Instead they potentially form a crucible where contentious ideas with educational merit may be creatively mediated (Osborn et al. 1997), where there is constructive engagement with curriculum development, and where teachers may achieve a high degree of agency in formulating practices that are both driven by carefully considered educational purposes, and which mitigate the excesses of a culture of performativity (Priestley et al. 2012). The difference between 'stuck' (Priestley et al. 2011) and 'bonded' (Siskin 1994) departments lies in the nature of the departments in question.

We make two points on this score. First, such teacher activism (Sachs 2003) would seem to be a necessary condition, if curricular initiatives such as CfE are to achieve their ambitions of being transformative (SE 2006). Second, teacher agency is achieved more readily when individual practitioners are situated within a web of productive relationships: relationships that are reciprocal and characterised by high levels of trust; and relationships that are sustained and purposive. We suggest that such relationships are enhanced by strong, supportive leadership. Although the relationship between the headteacher and the departments was asymmetric in some senses at Hill Brae, it was also supportive in a way that reduced risk and protected staff from unhelpful outside pressures. Interestingly in Hill Brae we found no evidence that significant relationships with external bodies helped shaped the curriculum. Coburn and Russell (2007) point to 
Fenwick, A., Minty, S. \& Priestley, M. (2013). Swimming against the tide: A case study of an integrated social studies department. Curriculum Journal.

tie span (the extending of relationship to people outside of the school, including experts) as a crucial factor in interrupting habitual frames of reference and forms of practice, but at Hill Brae, this impetus seemed to come mainly from the school leadership. We also suggest that the collegial professional relationships in Hill Brae were considerably facilitated by the spatial and material characteristics of the school.

Our research suggests that the department may be an important locus for innovation. New models of curriculum, such as $\mathrm{CfE}$, recognise this, in their assumption that teachers will become agents of change, and their reassertion of the professional role of the teacher as a developer of the curriculum. Nevertheless, there is little explicit recognition in such policy as to how such ends might be achieved, and there is little current research into the processes by which departments enact these new forms of curriculum integration. Future research might further explore teacher activism and agency within other departments of the same school. It may also be fruitful to return to Hill Brae post CfE.

\section{Note}

1. It is important to note that the term integrated is often misleading as it encompasses considerable variation in the degree of curricular cohesion and integration. Organisationally delivery may be integrated but minimal in relation to content and skills and vice-versa (Fogarty 1991).

2. Her Majesty's Inspectorate of Education was an executive agency of the Scottish Government, responsible for the inspection of public and independent, primary and secondary schools, as well as further education colleges, community learning, Local Authority Education Departments and teacher education. Learning and Teaching Scotland was merged with HMIE in July 2011 to form Education Scotland.

3. Only one Scottish university out of six presently offers a concurrent degree programme which ensures all students are qualified to teach two Social Studies. Three other universities offer a one year postgraduate qualification which can include classes in a second Social Studies subject but there is no placement allocation. Only a minority of students are eligible to attend these classes.

4. At the end of S4 (the fourth year of secondary), students normally sit examinations in eight Standard Grade subjects, which have been taken over 2 years. 
Fenwick, A., Minty, S. \& Priestley, M. (2013). Swimming against the tide: A case study of an integrated social studies department. Curriculum Journal.

\section{References}

Anthony, K. 2009. Were industrial towns 'death-traps'? Year 9 learn to question generalisations and to challenge their preconceptions about the 'boring' 19th century. Teaching History 135: 16-26.

Applebee A. N., M. Adler, and S. Flihan. 2007. Interdisciplinary Curricula in Middle and High School Classrooms: Case Studies of Approaches to Curriculum and Instruction. American Educational Research Journal 44, no. 4: 1002 -39.

Archer, M. 1988. Culture and Agency: the place of culture in social theory. Cambridge: Cambridge University Press.

Banham, D. 1998. Getting ready for the Grand Prix: Learning how to build a substantiated argument in Year 7. Teaching History 92: 6-15.

Bairner, J. 2008. Geography Education. In Scottish Education, eds. T. Bryce and W. Humes, 484-89. Edinburgh: Edinburgh University Press.

Ball, S., and C. Lacey. 1980. Subject disciplines as the opportunity for group action: A measured critique of subject subcultures. In Teacher strategies, ed. P. Woods, 149-77. London: Croom Helm.

Beane, J. A. 1997. Curriculum integration: designing the core of democratic education. New York: Teachers College Press.

Benavot, A. 2004. A global study of intended instructional time and official school curricula, 1980-2000. http://unesdoc.unesco.org/images/0014/001466/146625e.pdf (accessed October 4, 2011).

Bernstein, B. 1971. Class, Codes and Control: Theoretical Studies Towards a Sociology of Language. London: Routledge and Kegan Paul.

Biesta, G. 2004. Education, accountability and the ethical demand. Can the democratic potential of accountability be regained? Educational Theory 54, no. 3: 233-50.

Boyd, B. 2008. The Structure of the Secondary Curriculum Education. In Scottish Education, eds. T. Bryce and W. Humes, 425-34. Edinburgh: Edinburgh University Press.

Broadhead, P. 2001. Curriculum change in Norway: Thematic approaches, active learning and pupil co-operation - From curriculum design to classroom implementation. Scandinavian Journal of Educational Research, 45, no. 1: 1936.

Bryce, T. and W. Humes. 2008. Scottish Secondary Education: Philosophy and Practice. In Scottish Education, ed. T.G.K. Bryce and W.M. Humes, 33-46. Edinburgh: Edinburgh University Press.

Burnham, S. 2007. Getting Year 7 to set their own questions about the Islamic Empire, 600-1600. Teaching History 128: 11-17.

Clegg, C., K. Unsworth, O. Epitropaki, and G. Parker. 2002. Implicating trust in the innovation process. Journal of Occupational and Organizational Psychology 75: 409-22.

Coburn, C.E. and J.L. Russell. 2008. District policy and teachers' social Networks. Educational Evaluation and Policy Analysis 30, no. 3: 203-35.

Day, C., A. Kington, G. Stobart, and P. Sammons. 2006. The personal and professional selves of teachers: stable and unstable identities. British Educational Research Journal 32, no. 4: 601-616. 
Fenwick, A., Minty, S. \& Priestley, M. (2013). Swimming against the tide: A case study of an integrated social studies department. Curriculum Journal.

Elder-Vass, D. 2008. Integrating institutional, relational, and embodied structure: An emergentist perspective. British Journal of Sociology 59: 281-99.

Eisner, E. W. 1992. Curriculum ideologies. In Handbook of Research on Curriculum, ed. P.W. Jackson, 302-26. New York: Macmillan.

Exley, B. and P. Singh. 2011. Social Studies Disciplinary Knowledge: An Australian Case Study of Tensions between State Curriculum and National Assessment in Disadvantaged School Communities. In Disciplinarity: Functional Linguistic and Sociological Perspectives. Eds, F. Christie and K. Maton. London: Continuum.

Fogarty, R. 1991. 10 Ways to Integrate the Curriculum, Educational Leadership 47, no. 2: 61-65.

Foster, R. 2008. Speed cameras, dead ends, drivers and diversions: Year 9 use a 'road map' to problematise change and continuity. Teaching History 131: 4-8.

Geraedts, C., K.T. Boersma, and H.M.C. Eijkelhof. 2006. Towards coherent science and technology education. Journal of Curriculum Studies 38, no. 3: 307-25.

Hansen, K. H. 1999. The challenge of subject integration to teacher socialization and professional development. In Changing Schools/Changing Practices: perspectives on educational reform and teacher professionalism,eds. M. Lang, J. Olson, H. Hansen and W. Bunder, 141-48. Louvain: Garant.

Hargreaves, A. 1994a. Changing Teachers, Changing Times: Teachers' Work and Culture in the Postmodern Age. London: Cassell.

Hargreaves, A. 1994b. Restructuring restructuring: postmodernity and the prospects for educational change. Journal of Education Policy 9, no. 1: 47-65.

Hargreaves, A. and M. Fullan. 2000. Mentoring in the New Millennium. Theory into Practice 39, no. 1: 50-56.

Harris, R. and M. Ratcliffe. 2005. Socio-scientific issues and the quality of exploratory talk-what can be learned from schools involved in a 'collapsed day' project? The Curriculum Journal 16, no. 4: 439-53.

Harris, R., S. Harrison and R. McFann. 2011. Cross-Curricular Teaching and Learning in the Secondary School. London: Routledge.

Hillis, P. 2010. The position of history education in Scottish schools. The Curriculum Journal 21, no. 2: 141-60.

Jacobs, H. H. 1997. Mapping the big picture: Integrating curriculum and assessment $K$ 12. Alexandria, VA: Association for Supervision and Curriculum Development.

Jephcote, M. and B. Davies. 2007. School subjects, subject communities and curriculum change: the social construction of economics in the school curriculum. Cambridge Journal of Education 37, no. 2: 207-27.

Keddie, A., M. Mills and D. Pendergast. 2011. Fabricating and identity in neo-liberal times: Performing schooling as 'number one'. Oxford Review of Education, 37, no. 1: 75-92.

Kysilka, M.L. 1998. Understanding integrated curriculum. Curriculum Journal 9 no. 2: 197-209.

Kress, G. 2000. A Curriculum for the future. Cambridge Journal of Education, 30, no. 1: $133-145$.

Lambert, D. 2011. Reviewing the case for geography, and the 'knowledge turn' in the English National Curriculum. Curriculum Journal 22, no. 2: 243-64.

Little, J.W. 1995. Subject affiliation in high schools that restructure. In The subjects in question: Departmental organization and the high school, eds. L.S. Siskin and J.W. Little, 172-200. New York: Teachers College Press.

Leat, D. 1998. Thinking through Geography. Cambridge: Chris Kington Publishing. 
Fenwick, A., Minty, S. \& Priestley, M. (2013). Swimming against the tide: A case study of an integrated social studies department. Curriculum Journal.

Lévesque, S. 2008. Thinking Historically. Educating Students for the Twenty-First Century. Toronto: University of Toronto Press.

McGinley, B.P., and A. M. Grieve. 2011. Exploring educational interactions: a lesson for the development of interdisciplinary working? Journal of Vocational Education and Training 63, no. 1: 47-56.

McGregor, J. 2004 Space Power and the Classroom. FORUM 46, no. 1: 13-18.

Mintrop, H. 2004. Fostering constructivist communities of learners in the amalgamated multi-discipline of social studies. Journal of Curriculum Studies, 36, no.2: 141158.

Minty, S. and M. Priestley, 2011. School-Based Curriculum Development in Scotland: Curriculum Policy and Enactment. European Conference on Educational Research, Berlin, September 2011.

Moore, R. 2011. Making the Break: Disciplines and Interdisciplinarity. In Disciplinarity: Functional linguistic and sociological Perspectives, eds. F. Christie and K. Maton, 87-105. London: Continuum.

Monaghan, M. 2010. Having 'Great Expectations' of Year 9. Interdisciplinary work between English and history to improve pupils' historical thinking. Teaching History 138: 13-19.

Olson, J., E. James, and M. Lang. 1999. Changing the subject: the challenge of innovation to teacher professionalism in OECD countries, Journal of Curriculum Studies 31, no. 1: 69-82.

Osborn, M., P. Croll, P. Broadfoot, A. Pollard, E. McNess and P. Triggs. 1997. Policy into practice and practice into policy: Creative mediation in the primary classroom. In Teachers and the national curriculum, eds. G. Helsby and G. McCulloch, 52-65. London: Cassell.

Paechter, C. 1995. Crossing Subject Boundaries: the micropolitics of curriculum innovation. London: HMSO.

Priestley, M. and W. Humes. (2010) The Development of Scotland's Curriculum for Excellence: amnesia and déjà vu. Oxford Review of Education, 36, no.3: 345-61.

Priestley, M., K. Miller, L. Barrett, and C. Wallace. 2011. Teacher learning communities and educational change in Scotland: the Highland experience. British Educational Research Journal 37, no. 2: 265-84.

Priestley, M. and S. Minty. 2012. Curriculum for Excellence: 'A brilliant idea, but...' Paper presented at the European Conference of Educational Research, Cadiz, Spain September 2012.

Priestley, M., S. Robinson and G.J.J. Biesta. 2012. Teacher agency, performativity and curriculum change: Reinventing the teacher in the Scottish Curriculum for Excellence? In Performativity across UK education: ethnographic cases of its effects, agency and reconstructions, eds. Jeffrey, B. and Troman, G., 87-108. Painswick: EandE Publishing.

Priestley, M. 2009. Social Studies in Scotland's school curriculum: a case for a more integrated approach. Education in the North 17.

Priestley, M. 2010. Curriculum for Excellence: transformational change or business as usual? Scottish Educational Review 42, no. 1: 22-35.

Priestley, M. 2011. Schools, teachers and curriculum change: a balancing act? Journal of Educational Change 12, no. 1: 1-23.

Reeves, J. 2008. Between a rock and a hard place? Curriculum for Excellence and the Quality Initiative in Scottish schools. Scottish Educational Review 40, no. 2: 616. 
Fenwick, A., Minty, S. \& Priestley, M. (2013). Swimming against the tide: A case study of an integrated social studies department. Curriculum Journal.

Robertson, C., B. Cowell. and J. Olson. 1998. A case study of integration and destreaming: teachers and students in an Ontario school respond. Journal of Curriculum Studies 30, no. 6: 691-717.

Rudham, R. 2001. A noisy classroom is a thinking classroom: speaking and listening in Year 7 history. Teaching History, 105: 35-41.

Sachs, J. 2003. The Activist Teaching Profession, Buckingham, Open University Press

Scottish Executive. 2004. A curriculum for excellence - The curriculum review group, Edinburgh: Author.

Schien, E.H. 1992. Organizational Culture and Leadership. Jossey-Bass, San Francisco.

Siskin, L.S. 1994. Realms of Knowledge: Academic departments in secondary school. London: Falmer Press.

Siskin, L.S. and J.W. Little, eds. 1995. The subjects in question. Departmental organization and the high school. New York: Teachers' College Press.

Seixas, P., and C. Peck. 2004. Teaching historical thinking. In Challenges and Prospects for Canadian Social Studies, eds A. Sears and I. Wright, 109-117. Vancouver: Pacific Educational Press.

Sweerts, E. and J. Grice. 2002. Hitting the right note: how useful is the music of African-Amercians to historians? Teaching History, 108: 36-41.

Supovitz, J.A. 2008. Implementation as Iterative Refraction. In The Implementation gap: understanding reform in high schools, eds. J.A. Supovitz and E.H. Weinbaum, 1-21. New York: Teachers College Press.

Tyack, D. and L. Cuban, L. 1995. Tinkering toward utopia: a century of public school reform. Cambridge, Mass: Harvard University Press.

Venville, G. J., J. Wallace, L.J. Rennie and J. A. Malone. 2002. Curriculum Integration: Eroding the High Ground of Science as a School Subject? Studies in Science Education, 37:1, 43-83.

White, J. 2005. The Aims of School Education. http://www.ippr.org/uploadedFiles/research/projects/Education/The\%20Aims\% 20of\%20School\%20Ed\%20FINAL.pdf (accessed November 10, 2012).

Whitty, G. 2010. Revisiting school knowledge: some sociological perspectives on new school curricula. European Journal of Education, 45 no. 1: 28-44.

Wrenn, A., 1999. Build it in, don't bolt it on: history's opportunity to support critical citizenship, Teaching History, 96: 6-12.

Wubbels, T., and P. Poppleton. 1999. Knowledge about change and its effects on teachers. In Changing schools/changing practices: Perspectives on educational reform and teacher professionalism, eds. M. Lang, J. Olson, H. Hansen, and W. Bunder, 149-156. Louvain, BE: Garant.

Young, M. 2008. From Constructivism to Realism in the Sociology of the Curriculum. Review of Research in Education 32: 1-28.

Young, M., and J. Muller. 2010. Three Educational Scenarios for the Future: lessons from the sociology of knowledge. European Journal of Education 45, no. 1: 1227.

Acknowledgement

We would like to thank Dr Lesley Doyle of the University of Glasgow for gathering the data that contributed to this article. 